\title{
Comorbidities in a sample of adults with HIV in Puerto Rico: an exploratory study
}

This article was published in the following Dove Press journal:

HIVIAIDS - Research and Palliative Care

\author{
Carlos E Rodríguez-Díaz ${ }^{1,2}$ \\ Edda I Santiago-Rodríguez ${ }^{3}$ \\ Gerardo G Jovet-Toledo ${ }^{2}$ \\ Jorge Santana-Bagur ${ }^{4}$ \\ Yemile Ron-Suarez ${ }^{5}$ \\ Juan C Orengo ${ }^{6}$ \\ Felipe Arbelaez ${ }^{5}$ \\ Homero Monsanto 5 \\ 'The George Washington University, \\ Milken Institute School of Public Health, \\ Washington, DC, USA; ${ }^{2}$ University of \\ Puerto Rico-medical Sciences Campus, \\ School of Public Health, San Juan, PR, \\ USA; ${ }^{3}$ University of California, San \\ Francisco, Center for Aids Prevention \\ Studies, San Francisco, CA, USA; \\ ${ }^{4}$ University of Puerto Rico-medical \\ Sciences Campus, School of Medicine, \\ San Juan, PR, USA; ${ }^{5}$ Merck \& Co., Inc., \\ Medical Affairs, Carolina, PR, USA; \\ ${ }^{6}$ Ponce Health Sciences University, Public \\ Health Program, Ponce, PR, USA
}

Correspondence: Carlos E Rodríguez-Díaz The George Washington University, Milken Institute School of Public Health, $950 \mathrm{New}$ Hampshire Ave, Suite 300, DPCH,

Washington, DC 20052, USA

Tel + I 2029944532

Email carlosrd@gwu.edu
Background: Puerto Rico is among the areas with the highest estimated rates of people living with HIV in the United States. Despite the epidemiologic data available, there is limited real-world information that can help understand the comorbidities of people with HIV. In this study, we describe common comorbidities among adults with HIV attending treatment clinics in Puerto Rico.

Methods: An exploratory, retrospective, cross-sectional study was conducted at five HIV clinics in Puerto Rico. A random sample of medical records was reviewed. Descriptive statistics were used to summarize patient demographics, morbidity, and clinical characteristics. Multivariate analyses were conducted to explore comorbidities by age and sex.

Results: A total of 250 (179 men; 71 women) medical records were reviewed. Participants' mean age was 47.9 years and on average they had been living with HIV for 9 years. Most $(97.6 \%)$ had at least one comorbidity. The most common comorbidities were dyslipidemia and hypertension. Men were more likely to have been diagnosed with alcohol misuse while women were more likely to have been diagnosed with obesity, human papillomavirus (HPV), hypothyroidism, and osteoporosis. Participants younger than 50 years of age were more likely to have history of alcohol misuse while older individuals (50 years and old) were more likely to have been diagnosed with dyslipidemia, hypertension, and diabetes. Adjusting by sex and age, women were more likely to have been diagnosed with obesity and depression and those older than 50 years were more likely to have had a diagnosis of dyslipidemia, hypertension, HPV, and diabetes.

Conclusions: This is one of the few studies assessing comorbidities among adults with HIV in Puerto Rico, among Latino/Hispanics within the United States, and Latin America. Consistent with other studies, cardiovascular diseases are common among adults with HIV in Puerto Rico. Findings support the need for awareness and real-world evidence about comorbidities among people with HIV when implementing screenings and prescribing drugs.

Keywords: HIV, comorbidities, Puerto Rico

\section{Background}

HIV continues to be a significant public health issue, and despite advances in prevention and care services, further work is needed to improve the well-being of people living with HIV. Globally, in 2017, more than 940,000 people died of HIVrelated illnesses, 36.9 million were HIV-positive, and 1.8 million people became newly infected. ${ }^{1}$ By 2015, and according to the Centers for Disease Control and Prevention (CDC), ${ }^{2}$ Puerto Rico was among the areas with the highest estimated rates of adults and adolescents with diagnosed HIV infection $(17.1$ per 100,000) in the United States (US) and dependent areas. By May 2019, there were 49,675 known HIV infections in Puerto Rico. ${ }^{3}$ The incidence of HIV in the island is one of 
the highest rates in the United States ${ }^{4}$ and almost double the overall US Hispanic/Latino population. ${ }^{5,6}$

In Puerto Rico, the number of HIV/AIDS cases and the number of deaths have reduced substantially throughout the years, lowering the case fatality rate from $82 \%$ in 1985 to $2 \%$ in $2016 .^{7}$ Further, in a recent report by MarzánRodríguez and colleagues, ${ }^{8}$ it was documented that of all the deaths among people with HIV in Puerto Rico from 2006 to 2011 , less than a quarter $(23.5 \%)$ were related to HIV/AIDS.

People diagnosed with HIV infection may have an increased risk of developing comorbidities compared to the general population due to HIV disease itself and the use of long-term antiretroviral therapy (ART). ${ }^{9-20}$ As HIV survival has increased and persons living with HIV enjoy life expectancies similar to those without HIV infection, they are likely to share the same comorbidities. For example, heart disease is among the comorbidities typically seen among people with HIV. ${ }^{21-24}$ Coincidentally, heart disease was the second leading cause of death in Puerto Rico in 2013. ${ }^{25}$ Furthermore, the Behavioral Risk Factor Surveillance System (BRFSS) has evidenced relatively high prevalence of high cholesterol (36.7), hypertension (44.7), and diabetes (17.2\%) among adult residents in Puerto Rico. ${ }^{26}$ In addition, nearly two-thirds are either overweight or obese, a risk factor for Coronary Heart Disease (CHD), and $43.4 \%$ has been estimated to have metabolic syndrome. ${ }^{27}$ In a recent assessment of CHD risk of patients attending physician offices in Puerto Rico, a substantial number of patients whose records were reviewed had risk factors for developing CHD and nearly one-third of the sample had a $10 \%$ or more 10 -year risk of developing CHD. ${ }^{28}$

In spite of the availability of mortality and prevalence data, there is a lack of real-world published information that would help to understand the comorbidities of people with HIV in Puerto Rico. Such information is of great importance to create awareness among health care providers and the health care system overall about the needs of taking into consideration the comorbidities of people with HIV when planning screening tests and prescribing any medication that they may need.

\section{Methods}

To understand comorbidities in a sample of adult HIVpositive individuals in Puerto Rico, an exploratory, retrospective, cross-sectional study was conducted between January and April 2015. Data were collected from five clinics that provide services to people with HIV in different geographical areas in Puerto Rico. Clinics were purposively chosen to provide diversity to the sample and based on disposition to collaborate in the study. A State Health Department HIV Clinic, a Municipal Health Department HIV Clinic, and three private/non-governmental HIV Clinics provided the sample for the study. Both publicly funded and private-owned clinics were included.

\section{Sample}

A random sample of medical records was reviewed. At each clinic, a simple random selection was used to select medical records to be reviewed. The eligibility criteria to select and review a medical record included having an HIV diagnosis, at least 21 years of age, and being engaged in care in the selected clinic during the last 6 months. Patients with an AIDS diagnosis and pregnant women were excluded from the study due to additional medical conditions associated with their health status. Similarly, individuals enrolled in clinical trials at the time of data collection or during the last six months prior to their medical chart revision were excluded from the sample.

\section{Measurements}

Following an extensive narrative literature review and clinician's recommendations, an in-depth data collection instrument was created, allowing for the recollection of HIV clinical information, as well as patient history of numerous comorbidities, lipids, glucose and creatinine data, and comorbidities treatment history. Patient's demographic information were also collected. All data collected were based on the information available in the medical record of each patient at the selected clinics. Comorbidities were collected from the medical record using different sources of information, including problem list, referral notes, and progress notes.

\section{Analysis}

Data collection was completed using a paper and pen survey-like instrument, and then data were transferred to an electronic dataset using the Questionnaire Development System (QDS, Nova Research Company). Descriptive statistics (ie, mean, standard deviation) was used to summarize patient demographics, morbidity, and clinical characteristics. Multivariate analyses (ie, MANOVA, Multiple Regression Analysis) were conducted to explore differences by age and sex. For age-related analysis, 50 years of age were selected to dichotomize the sample and 
this is consistent with CDC definition of older people with HIV. ${ }^{29}$ SPSS v.20 was used to conduct all statistical procedures. Authorization was sought and received from each clinic before submitting to the Institutional Review Board (IRB). All study procedures were approved by the Human Research Subjects Protection Office of the University of Puerto Rico-Medical Sciences Campus.

\section{Results}

\section{Demographic and clinical characteristics}

As included in Table 1, a total of 250 medical records were reviewed. Of these, 179 were of men (71.6\%) and 71 $(28.4 \%)$ of women. The mean age of the subjects was 47.9 years and, on average, they had been living with HIV for 9.3 years. Data availability for this research did not differ by sex. Certainly, as a result of good practices in HIV care, patients who have been living longer with a diagnosis of HIV infection had more information in their medical records.

On average, the age for HIV diagnosis among participants was 38 years; they spent 9.4 years from HIV diagnosis to treatment initiation and have been on treatment for 3.4 years. The mean CD4 count was 723.8 cells $/ \mathrm{mm}^{3}$, and for viral load, the count was 3,431.1 copies/mL.

Considering the role that body max index (BMI) may have with certain comorbidities, bivariate analyses were conducted to assess the BMI by sex and age. As included in Table 2, more than a third of the study sample was overweight. Among men, $62.6 \%$ had an abnormal BMI, while $35.2 \%$ of the women were obese. These differences were statistically significant by sex.

When BMI was assessed by age groups (younger than 50 years of age and 50 years of age and older), more than a third (37.0\%) of those younger than 50 years of age had a normal BMI, and $40.4 \%$ of those 50 years of age or older were overweight. These differences by age groups were not found to be statistically significant. See Table 2 for details.

\section{Comorbidities}

The vast majority (97.6\%) of the participants had been diagnosed with at least one HIV comorbidity during the 6-month period that preceded data collection. Among the most common comorbidities for both men and women were dyslipidemia (total: 60.8\%; men: 60.8\%; women: 69.0\%), alcohol abuse (total: 48.8\%; men: 58.1\%; women: $25.4 \%$ ), and hypertension (total; 39.6\%; men: 36.9\%; women: $46.5 \%$ ). Table 3 includes all the comorbidities found in the study sample. In general, the mean amount of comorbidities reported in the sample was $3.7(\mathrm{SD}=1.9)$. Men reported significantly less comorbidities (Mean=3.5, $\mathrm{SD}=1.9$ ) than women $(\mathrm{Mean}=4.1, \mathrm{SD}=1.9 ; p=0.035)$.

As included in Table 3, when all comorbidities where assessed by sex, men were more likely to have been diagnosed with alcohol misuse $(p<0.001)$ while women were more likely to have been diagnosed with obesity $(p=0.001)$, HPV infection $(p=0.002)$, hypothyroidism $(p=0.006)$, and osteoporosis $(p=0.003)$.

Table I General characteristics of a sample of adults with HIV in Puerto Rico

\begin{tabular}{|c|c|c|c|c|c|c|}
\hline \multirow[t]{2}{*}{ Characteristics } & \multicolumn{2}{|c|}{ Total $(\mathrm{N}=\mathbf{2 5 0})$} & \multicolumn{2}{|c|}{ Men $(N=\mid 79)$} & \multicolumn{2}{|c|}{ Women $(\mathbf{N}=7 \mathrm{I})$} \\
\hline & $\mu$ & SD & $\mu$ & SD & $\mathbf{M}$ & SD \\
\hline Age & 47.9 & 12.6 & 46.3 & 13.3 & 51.8 & 9.8 \\
\hline Weight (lbs) & 169.9 & 38.7 & 170.7 & 34.0 & 168.1 & 48.7 \\
\hline Height (in) & 67.4 & 6.0 & 69.0 & 6.2 & 63.3 & 2.7 \\
\hline Body mass index & 26.6 & 6.0 & 25.5 & 5.0 & 29.3 & 7.4 \\
\hline Age when diagnosed with HIV & 38.0 & 11.6 & 37.0 & 12.0 & 40.6 & 9.8 \\
\hline Age of HIV treatment initiation ${ }^{\mathrm{a}}$ & 39.6 & 12.5 & 37.7 & 13.1 & 44.7 & 9.3 \\
\hline Diagnosis to HIV treatment (months) & 9.4 & 17.1 & 9.0 & 15.5 & 10.6 & 20.8 \\
\hline Years living with HIV & 9.3 & 8.1 & 8.8 & 8.0 & 10.6 & 8.0 \\
\hline Years in HIV treatment ${ }^{\mathrm{a}}$ & 3.4 & 3.6 & 3.0 & 3.6 & 4.2 & 3.4 \\
\hline Days since last CD4 test & 80.2 & 75.7 & 79.8 & 65.2 & 81.1 & 97.6 \\
\hline CD4 count (cells $/ \mathrm{mm}^{3}$ ) & 723.8 & 363.2 & 698.7 & 326.8 & 786.6 & 437.6 \\
\hline CD4 percentage & 34.8 & 30.4 & 34.6 & 35.1 & 34.9 & 30.4 \\
\hline Days since last viral load test & 81.4 & 84.6 & 82.7 & 76.7 & 78.1 & 102.2 \\
\hline Viral load count ${ }^{\mathrm{b}}$ (copies/mL) & 3431.1 & $14,342.9$ & 4174.3 & $16,670.5$ & 1628.7 & 5348.1 \\
\hline
\end{tabular}

Notes: ${ }^{\mathrm{a}} \mathrm{N}=103$ (Men=74, Women=29). ${ }^{\mathrm{b}} \mathrm{n}=137$ (Men=97, Women=40). 
Table 2 Bivariate analysis of body mass index categorized by sex and age in a sample of adults with HIV in Puerto Rico

\begin{tabular}{|c|c|c|c|c|c|c|c|c|c|c|c|c|}
\hline \multirow[t]{2}{*}{ Comorbidity } & \multicolumn{2}{|c|}{ Total $(\mathrm{N}=\mathbf{2 5 0})$} & \multicolumn{2}{|c|}{ Men $(N=179)$} & \multicolumn{2}{|c|}{ Women $(\mathbf{N}=7 \mathrm{I})$} & \multirow[t]{2}{*}{$p$-Value } & \multicolumn{2}{|c|}{$<50$ yrs $(N=135)$} & \multicolumn{2}{|c|}{$50+$ yrs $(N=1 \mid 4)$} & \multirow[t]{2}{*}{$p$-Value } \\
\hline & $\mathbf{N}$ & $\%$ & $\mathbf{n}$ & $\%$ & $\mathbf{n}$ & $\%$ & & $\mathbf{n}$ & $\%$ & $\mathbf{n}$ & $\%$ & \\
\hline Body mass index & & & & & & & 0.001 & & & & & 0.360 \\
\hline$<20$ & 26 & 10.4 & 21 & 11.7 & 5 & 7.0 & & 12 & 8.9 & 14 & 12.3 & \\
\hline $20-<25$ & 84 & 33.6 & 67 & 37.4 & 17 & 23.9 & & 50 & 37.0 & 33 & 28.9 & \\
\hline $25-<30$ & 90 & 36.0 & 66 & 36.9 & 24 & 33.8 & & 44 & 32.6 & 46 & 40.4 & \\
\hline $30+$ & 50 & 20.0 & 25 & 14.0 & 25 & 35.2 & & 29 & 21.5 & 21 & 18.4 & \\
\hline
\end{tabular}

Note: Values in bold represent statistical significance $(<0.05)$.

Table 3 Comorbidities in a sample of adults with HIV in Puerto Rico

\begin{tabular}{|c|c|c|c|c|c|c|c|}
\hline \multirow[t]{2}{*}{ Comorbidity } & \multicolumn{2}{|c|}{ Total } & \multicolumn{2}{|c|}{ Men $(N=179)$} & \multicolumn{2}{|c|}{ Women (N=7I) } & \multirow[t]{2}{*}{$p$-Value } \\
\hline & $\mathbf{n}$ & $\%$ & $\mathbf{n}$ & $\%$ & $\mathbf{N}$ & $\%$ & \\
\hline Prevalence of comorbidities & 244 & 97.6 & 174 & 97.2 & 70 & 98.6 & 0.519 \\
\hline Dyslipidemia & 152 & 60.8 & 103 & 57.5 & 49 & 69.0 & 0.094 \\
\hline Alcohol miuse & 122 & 48.8 & 104 & 58.1 & 18 & 25.4 & $<0.001$ \\
\hline Hypertension & 99 & 39.6 & 66 & 36.9 & 33 & 46.5 & 0.161 \\
\hline Cigarette Smoking & 89 & 35.6 & 67 & 37.4 & 22 & 31.0 & 0.337 \\
\hline Overweight & 67 & 26.8 & 46 & 25.7 & 21 & 29.6 & 0.532 \\
\hline Diabetes mellitus & 49 & 19.6 & 32 & 17.9 & 17 & 23.9 & 0.276 \\
\hline Depression & 48 & 19.2 & 29 & 16.2 & 19 & 26.8 & 0.056 \\
\hline Obesity & 48 & 19.2 & 25 & 14.0 & 23 & 32.4 & 0.001 \\
\hline Substance misuse & 42 & 16.8 & 33 & 18.4 & 9 & 12.7 & 0.272 \\
\hline Human papilloma virus (HPV) & 42 & 16.8 & 22 & 12.3 & 20 & 28.2 & 0.002 \\
\hline Chronic hepatitis C & 33 & 13.2 & 24 & 13.4 & 9 & 12.7 & 0.878 \\
\hline Vitamin D deficiency & 24 & 9.6 & 15 & 8.4 & 9 & 12.7 & 0.298 \\
\hline Hypothyroidism & 20 & 8.0 & 9 & 5.0 & 11 & 15.5 & 0.006 \\
\hline Chronic hepatitis B & 12 & 4.8 & 7 & 3.9 & 5 & 7.0 & 0.330 \\
\hline Chronic kidney disease & 10 & 4.0 & 5 & 2.8 & 5 & 7.0 & 0.153 \\
\hline Lipodystrophy & 9 & 3.6 & 8 & 4.5 & 1 & 1.4 & 0.452 \\
\hline Osteoporosis & 9 & 3.6 & 2 & 1.1 & 7 & 9.9 & 0.003 \\
\hline Benign prostatic hyperplasia & 7 & 2.8 & 7 & 3.9 & - & - & - \\
\hline Peripheral vascular disease & 6 & 2.4 & 5 & 2.8 & I & 1.4 & 0.999 \\
\hline Revascularization Procedure & 6 & 2.4 & 4 & 2.2 & 2 & 2.8 & 0.999 \\
\hline Acute coronary syndrome (ACS) & 5 & 2.0 & 5 & 2.8 & 0 & - & 0.326 \\
\hline Pre-diabetes & 5 & 2.0 & 3 & 1.7 & 2 & 2.8 & 0.624 \\
\hline Angina pectoris & 4 & 1.6 & 3 & 1.7 & 1 & 1.4 & 0.999 \\
\hline Previous stroke/TIA & 2 & 0.8 & 0 & - & 2 & 2.8 & 0.080 \\
\hline Congestive heart failure & 1 & 0.4 & I & 0.6 & 0 & - & 0.999 \\
\hline
\end{tabular}

Note: Values in bold represent statistical significance $(<0.05)$.

The data collection instrument also included a general clinical assessment of indicators of common comorbidities and chronic conditions. As included in Table 4, data on blood pressure, lipid panel, and blood chemistry tests were obtained from medical records. Overall, the research sample showed slightly higher levels for triglycerides, glucose, hemoglobin A1c, and systolic blood pressure when compared to normal values. When analyzed by sex, women had LDL levels slightly higher than normal. There were no statistically significant findings when these clinical indicators were assessed by age.

As included in Table 5, the most common comorbidity treatments were multivitamins (71.5\%), lipid-lowering therapy (57.6\%), and antihypertensive agents (37.6\%). These were also the most common treatments when stratified by sex. The mean amount of medications in the study sample 
Table 4 Blood pressure, lipid panel, and blood chemistry tests data from a sample of adults with HIV in Puerto Rico

\begin{tabular}{|c|c|c|c|c|c|c|}
\hline \multirow[t]{2}{*}{ Clinical indicator } & \multicolumn{2}{|c|}{ Total $(\mathbf{N}=\mathbf{2 5 0})$} & \multicolumn{2}{|c|}{ Men $(N=179)$} & \multicolumn{2}{|c|}{ Women $(\mathbf{N}=7 I)$} \\
\hline & $\mu$ & SD & $\mathbf{M}$ & SD & $\mu$ & SD \\
\hline Non-HDL ${ }^{\mathrm{a}}$ & 36.7 & 31.0 & 37.5 & 32.0 & 35.0 & 29.3 \\
\hline Total cholesterol & 177.9 & 41.7 & 175.0 & 42.5 & 185.3 & 38.8 \\
\hline HDL & 46.1 & 16.1 & 44.6 & 14.8 & 50.0 & 18.4 \\
\hline LDL & 99.8 & 34.1 & 98.3 & 34.2 & 103.7 & 33.7 \\
\hline Triglycerides & 185.7 & 179.1 & 191.3 & 194.9 & 171.7 & 131.7 \\
\hline Glucose (FPG) & 101.6 & 33.1 & 101.4 & 31.3 & 101.9 & 131.7 \\
\hline Hemoglobin Alc (HgbAlc) $)^{b}$ & 6.1 & 1.5 & 6.2 & 1.7 & 6.1 & 0.9 \\
\hline \multicolumn{7}{|l|}{ Blood pressure } \\
\hline Systolic & 128.3 & 17.5 & 127.6 & 16.4 & 130.1 & 19.8 \\
\hline Diastolic & 79.4 & 10.7 & 79.0 & 11.0 & 80.4 & 10.0 \\
\hline Creatinine $(\mathrm{Cr})$ & 1.0 & 0.6 & 1.0 & 0.6 & 0.8 & 0.7 \\
\hline
\end{tabular}

Notes: ${ }^{a} \mathrm{~N}=167$ (Male=II3; Female=54). ${ }^{\mathrm{b}} \mathrm{n}=93$ (Male=65; Female=28).

Table 5 Treatment history of a sample of adults with HIV in Puerto Rico

\begin{tabular}{|c|c|c|c|c|c|c|c|}
\hline \multirow[t]{2}{*}{ Treatment } & \multicolumn{2}{|c|}{ Total $(\mathrm{N}=\mathbf{2 5 0})$} & \multicolumn{2}{|c|}{ Men $(N=\mid 79)$} & \multicolumn{2}{|c|}{ Women $(\mathbf{N}=7 \mathrm{I})$} & \multirow[t]{2}{*}{$p$-Value } \\
\hline & $\mathbf{n}$ & $\%$ & $\mathbf{n}$ & $\%$ & $\mathbf{n}$ & $\%$ & \\
\hline Anti-acids & 8 & 3.2 & 3 & 1.7 & 5 & 7.0 & 0.030 \\
\hline Antihyperglycemic agents & 41 & 16.4 & 30 & 16.8 & 11 & 15.5 & 0.807 \\
\hline Antihypertensive agents & 94 & 37.6 & 63 & 35.2 & 31 & 43.7 & 0.213 \\
\hline Asthma medications & 28 & 11.2 & 17 & 9.5 & II & 15.5 & 0.175 \\
\hline Cholecalciferol & 80 & 32.0 & 51 & 28.5 & 29 & 40.8 & 0.059 \\
\hline Dehydroepiandrosterone & 3 & 1.2 & 3 & 1.7 & 0 & - & - \\
\hline $\mathrm{H} 2$ blockers & 42 & 16.8 & 25 & 14.0 & 17 & 23.9 & 0.057 \\
\hline Levothyroxine & 15 & 6.0 & 7 & 3.9 & 8 & 11.3 & - \\
\hline Lipid-lowering therapy & 144 & 57.6 & 97 & 54.2 & 47 & 66.2 & 0.083 \\
\hline Multivitamins & 178 & 71.5 & 123 & 68.7 & 55 & 78.6 & 0.121 \\
\hline Opioid pain medication & 2 & 0.8 & 2 & I.I & 0 & - & - \\
\hline Proton pump inhibitors & 46 & 18.4 & 21 & 11.7 & 25 & 35.2 & $<0.001$ \\
\hline
\end{tabular}

Note: Values in bold represent statistical significance $(<0.05)$.

was of $2.1(\mathrm{SD}=16)$. Men were using less medications $($ Mean $=2.5, \mathrm{SD}=1.5)$ than women $($ Mean $=3.5, \mathrm{SD}=1.6$, $p<0.001)$.

Further, when compared to men, women were more likely to be using proton pump inhibitors $(p<0.001)$ and anti-acids ( $p=0.030$, See Table 5).

To explore age-related factors associated with comorbidities, the sample was dichotomized in two age groups, younger than 50 years of age and 50 years of age and older. As included in Table 6, the group younger than 50 years were more likely to have an alcohol abuse diagnosis ( $p=0.006)$ while the older individuals (50 years of age or older) were more likely to have been diagnosed with dyslipidemia $(p<0.001)$, hypertension $(p<0.001)$, and diabetes mellitus $(p<0.001)$.

Considering the role of age in developing comorbidities, a multivariate analysis adjusting by sex and age was conducted. Findings suggest that women were more likely than men to have been diagnosed with obesity $(\mathrm{aOR}=3.197 ; 95 \%$ CI: $1.625-6.290)$ and depression $(\mathrm{aOR}=1.986$; 95\% CI: 1.008-3.914). Also, as included in Table 7, they were slightly more likely than men to have been diagnosed with alcohol abuse $(\mathrm{aOR}=0.266$; 95\% CI: 0.143-0.496), HPV infection $\quad(\mathrm{aOR}=0.282 ; 95 \% \quad \mathrm{CI}: 0.136-0.584)$, and hypothyroidism $\quad(\mathrm{aOR}=0.300 ; 95 \% \quad \mathrm{CI}: \quad 0.116-0.779)$. Comorbidities associated with been older than 50 years of 
Table 6 Bivariate analysis of the prevalence of comorbidities by age in a sample of adults with HIV in Puerto Rico

\begin{tabular}{|c|c|c|c|c|c|}
\hline \multirow{2}{*}{ Comorbidity } & \multicolumn{2}{|c|}{$<50$ yrs $(\mathrm{N}=135)$} & \multicolumn{2}{|c|}{$50+$ yrs $(N=|| 4)$} & \multirow[t]{2}{*}{ p-Value } \\
\hline & $\mathbf{n}$ & $\%$ & $\mathbf{N}$ & $\%$ & \\
\hline Prevalence of comorbidities & $|3|$ & 97.0 & 113 & 99.1 & 0.242 \\
\hline Alcohol abuse & 77 & 57.0 & 45 & 39.5 & 0.006 \\
\hline Dyslipidemia & 66 & 48.9 & 86 & 75.4 & $<0.001$ \\
\hline Cigarette smoking & 55 & 40.7 & 34 & 29.8 & 0.073 \\
\hline Hypertension & 38 & 28.1 & 61 & 53.5 & $<0.001$ \\
\hline Overweight & 34 & 25.2 & 33 & 28.9 & 0.505 \\
\hline HPV & 28 & 20.7 & 14 & 12.3 & 0.076 \\
\hline Substance misuse & 27 & 20.0 & 15 & 13.2 & 0.151 \\
\hline Obesity & 27 & 20.0 & 21 & 18.4 & 0.753 \\
\hline Depression & 27 & 20.0 & 21 & 18.4 & 0.753 \\
\hline Diabetes mellitus & 15 & II.I & 34 & 29.8 & $<0.001$ \\
\hline Chronic hepatitis C & 13 & 9.6 & 20 & 17.5 & 0.067 \\
\hline Vitamin D deficiency & 10 & 7.4 & 14 & 12.3 & 0.194 \\
\hline Hypothyroidism & 9 & 6.7 & 11 & 9.6 & 0.388 \\
\hline Chronic hepatitis B & 7 & 5.2 & 5 & 4.4 & 0.769 \\
\hline Angina pectoris & 3 & 2.2 & I & 0.9 & 0.627 \\
\hline Chronic kidney disease & 3 & 2.2 & 7 & 6.1 & 0.193 \\
\hline Revascularization procedure & 2 & 1.5 & 4 & 3.5 & 0.417 \\
\hline Pre-diabetes & 2 & 1.5 & 3 & 2.6 & 0.663 \\
\hline Lipodystrophy & 2 & 1.5 & 7 & 6.1 & 0.084 \\
\hline Osteoporosis & 2 & 1.5 & 7 & 6.1 & 0.084 \\
\hline Benign prostatic hyperplasia $^{a}$ & 2 & 1.9 & 5 & 7.1 & 0.114 \\
\hline Previous stroke/TIA & 1 & 0.7 & I & 0.9 & 0.999 \\
\hline Peripheral vascular disease & 1 & 0.7 & 5 & 4.4 & 0.096 \\
\hline Acute coronary syndrome (ACS) & 0 & - & 5 & 4.4 & 0.019 \\
\hline Congestive heart failure & 0 & - & I & 0.9 & 0.458 \\
\hline Tuberculosis & 0 & - & 0 & - & - \\
\hline Fat accumulation & 0 & - & 0 & - & - \\
\hline
\end{tabular}

Notes: ${ }^{a}$ Only men were included when analyzing benign prostatic hyperplasia $(n=178)$. Values in bold represent statistical significance $(<0.05)$.

age were dyslipidemia $(\mathrm{aOR}=3.075 ; 95 \% \mathrm{CI}: 1.769-5.346)$, hypertension $(\mathrm{aOR}=2.852$; 95\% CI: $1.670-4.871)$, HPV infection $(\mathrm{aOR}=2.547 ; 95 \% \mathrm{CI}: 1.205-5.385)$, and diabetes mellitus (aOR=3.331; 95\% CI: 1.684-6.589).

\section{Discussion}

While not a representative sample of people with HIV in Puerto Rico, data from participants in this study are similar to the general epidemiological data available of people with HIV and to other studies conducted among people with HIV in Puerto Rico. The ratio of women and men with HIV in the sample (1:3) is consistent with surveillance data from the Puerto Rico Department of Health. ${ }^{7}$ Other general similarities with previously published research are participant's average age $e^{30,31}$ and hemoglobin levels. ${ }^{32}$
Consistent with other studies among people with HIV, the sample studied in this research evidenced comorbidities associated with cardiovascular diseases. ${ }^{33}$ For example, dyslipidemia is a comorbidity reported among other similar populations. In our study, the prevalence of dyslipidemia was higher than the rates reported among HIV-positive adults (43.7\% Latinos) in the Bronx, NY (60.8\% vs $48 \%)$. $^{33}$

The five most common comorbidities in this sample of people with HIV in Puerto Rico slightly varied from the findings from a study published by Miranda and colleagues ${ }^{34}$ also encompassing a sample of HIV-positive individuals in the island. In their longitudinal study among people with HIV, they found that the most common comorbidities were cardiovascular diseases, renal and hepatic disorders, osteopenia, endocrine and metabolic abnormalities, and non-AIDS defining neoplasm. The difference between these studies might be the inclusion/exclusion of patients with an AIDS diagnosis and 
Table 7 Multivariate analysis of the prevalence of comorbidities by age and sex in a sample of adults with HIV in Puerto Rico ${ }^{a}$

\begin{tabular}{|c|c|c|c|c|}
\hline \multirow[t]{3}{*}{ Comorbidity } & \multicolumn{2}{|l|}{ Sex } & \multirow[b]{2}{*}{$<50$ yrs } & \multirow{2}{*}{$\begin{array}{l}\text { Age } \\
50+\text { yrs }\end{array}$} \\
\hline & Men & Women & & \\
\hline & Ref. & aOR (95\% Cl) & Ref. & aOR $(95 \% \mathrm{Cl})$ \\
\hline Prevalence of comorbidities & I & $1.258(0.133-11.891)$ & I & $3.313(0.354-31.040)$ \\
\hline Alcohol abuse & I & $0.266(0.143-0.496)$ & I & $0.595(0.349-1.013)$ \\
\hline Dyslipidemia & I & $1.288(0.697-2.379)$ & 1 & 3.075 (1.769-5.346) \\
\hline Cigarette smoking & I & $0.821(0.450-1.498)$ & 1 & $0.64 \mid(0.374-1.098)$ \\
\hline Hypertension & I & $1.181(0.658-2.119)$ & I & $2.852(1.670-4.87 I)$ \\
\hline Overweight & I & $1.162(0.623-2.168)$ & I & I.I77 (0.663-2.088) \\
\hline HPV & I & $0.282(0.136-0.584)$ & I & 2.547 (1.205-5.385) \\
\hline Drug abuse & I & $0.703(0.3|2-1.58|)$ & I & $0.644(0.320-1.298)$ \\
\hline Obesity & I & $3.197(1.625-6.290)$ & I & $0.700(0.357-1.372)$ \\
\hline Depression & I & $1.986(1.008-3.914)$ & I & $0.785(0.407-|.5| 4)$ \\
\hline Diabetes mellitus & I & I.II 8 (0.558-2.240) & I & 3.331 (1.684-6.589) \\
\hline Chronic hepatitis C & I & $0.790(0.340-1.836)$ & I & $2.085(0.97 \mid-4.474)$ \\
\hline Vitamin $D$ deficiency & I & $0.706(0.288-1.733)$ & I & $0.611(0.255-1.462)$ \\
\hline Hypothyroidism & I & $0.300(0.116-0.779)$ & I & $0.859(0.33 \mathrm{I}-2.230)$ \\
\hline Chronic hepatitis B & 1 & $1.990(0.591-6.707)$ & I & $0.727(0.217-2.439)$ \\
\hline Angina pectoris & I & $1.020(0.100-10.432)$ & I & $0.388(0.038-3.94 I)$ \\
\hline Chronic kidney disease & I & $2.175(0.592-7.992)$ & I & $2.46 \mid(0.603-10.047)$ \\
\hline Revascularization procedure & I & $1.046(0.181-6.054)$ & I & $2.398(0.418-13.768)$ \\
\hline Pre-diabetes & I & $1.513(0.237-9.656)$ & I & $1.655(0.261-10.516)$ \\
\hline Lipodystrophy & I & $0.217(0.026-1.808)$ & I & $5.348(1.073-26.656)$ \\
\hline Osteoporosis & I & $7.831(1.548-39.622)$ & I & $2.929(0.573-14.986)$ \\
\hline Peripheral vascular disease & I & $0.345(0.039-3.075)$ & I & $7.202(0.816-63.535)$ \\
\hline
\end{tabular}

Notes: ${ }^{a}$ Acute coronary syndrome, congestive heart failure, tuberculosis, previous stroke/TIA, and fat accumulation were excluded from this analysis due to lack of reported cases in certain subgroups. Benign prostatic hyperplasia was also excluded from the analysis. Values in bold represent statistical significance $(<0.05)$.

the longitudinal nature of the study conducted by Miranda and colleagues. ${ }^{34}$ It is our understanding that our findings illustrate a better picture of the comorbidities of people with HIV in Puerto Rico who are engaged in care.

Another study conducted among people with HIV in Puerto Rico found morbidity and mortality associated with kidney disease. ${ }^{30}$ However, in this sample, history of comorbidity with kidney disease was low $(<20 \%)$ and no alarming levels of clinical indicators of kidney disease (ie, creatinine) were reported.

Consistent with other research findings from studies with people with HIV, when compared to men, women show higher rates of overweight and obesity. ${ }^{31,35}$ A study conducted by Ramirez-Marrero and colleagues ${ }^{36}$ reported the risk for metabolic syndrome among people with HIV in Puerto Rico. Consistent with their findings, our analysis supports the needs for monitoring cardiovascular indicators among people with HIV. Furthermore, our findings consistent with those of Maldonado-Martínez and colleagues $^{35}$ from a sample of people with HIV in Puerto
Rico - support the needs for comprehensive approaches to reduce the risk for metabolic syndrome and HIV disease progression, including monitoring BMI as well as chronic and behavioral precursors.

The most common comorbidities found in older groups after controlling by sex are consistent with findings reported in the scientific literature. A significant finding in this regard is the fact that dyslipidemia among those participants 50 years and older was 3.075 (95\% CI: 1.7695.346) more common than among those younger than 50 years. This is more than double the likelihood of this correlation $(\mathrm{OR}=1.42)$ found in a sample of individuals 45 years or older from The Bronx, New York. ${ }^{33}$ Future studies among patients older than 50 years are recommended to assess HIV-induced accelerated aging.

While the purpose of this study was not to assess HIV comorbidities with mental illnesses in details, significant rates of depression and substance abuse were found. Due to the fact that injecting drug use is one of the main risk factors for HIV infection in Puerto Rico, it is not surprising 
to identify these comorbidities in a sample of people with HIV in the archipelago. In our study, $48.8 \%$ of the sample reported alcohol misuse. In other studies of people with HIV, alcohol use had varied from 5\% (measuring alcohol abuse) to $51.5 \% .^{32,33,37}$ Nonetheless, different from other investigations conducted in Puerto Rico, ${ }^{34,35}$ in our study we found that, after adjusting by age and sex, women had higher likelihood of been diagnosed with alcohol misuse. This finding, as other findings reported in this manuscript, requires further analysis considering the role that sex differences may play in access and healthcare use. ${ }^{38}$

On the other hand, cigarette smoking was reported among more than a third of the participants (35.6\%) and substance misuse was documented in $16.8 \%$ of the study sample. Other studies have reported rates from $13 \%$ to $59.4 \%$ of cigarette smoking ${ }^{33,36,39}$ and from 3\% (reporting only drug abuse) to $43.7 \%$ of substance misuse. ${ }^{32,33}$ The findings of our study are consistent with those from other studies reporting higher rates of substance misuse (nonalcohol or cigarettes) among men. ${ }^{34,35}$

Findings from this study should be considered in context with population-based data available regarding the most common comorbidities in Puerto Rico. For example, it has been documented that among adults in Puerto Rico (irrespective of their HIV status) about 36.7\% (36.6\% among men; 36.7\% among women) have reported a high level of cholesterol in blood;13.1\% (20.5\% among men; $6.8 \%$ among women) have reported binge drinking; $11.3 \%$ have reported current smoker status (16.9\% among men; $6.4 \%$ among women); and $68.3 \%$ of the population is overweight or obese $(70.2 \%$ among men; $66.6 \%$ among women). ${ }^{26}$ These population trends have an impact in the assessment of comorbidities among people with HIV in Puerto Rico and the interpretation and comparisons with findings from studies conducted with populations elsewhere. Moreover, these population health indicators highlight the significance of the findings of this study and the need to integrate public health prevention efforts.

Research findings should be considered within the limitations of this study. This research project was limited to the revision of 250 medical charts from 5 clinics. These clinics were selected following a purposive sampling approach and the 250 medical charts reviewed were chosen based on a simple random selection. Further, due to the retrospective and cross-sectional nature of this study, data are limited to the information available from the chart reviews. No data were collected related to the use of ART limiting the analysis of the relationship of HIV-related medication and comorbidities. Similarly, the charts selected for revision are of those participants who met inclusion criteria and were active in medical care. As a result of all the aforementioned limitations, findings are not generalized to people with HIV in Puerto Rico or elsewhere.

\section{Conclusion}

Based on a comprehensive narrative analysis of the scientific literature, and to the best of our knowledge, this is the first observational study that assessed comorbidities among people with HIV in Puerto Rico and one of the few among Latino/Hispanic populations. Despite the limitations of the study and consistent with other studies, cardiovascular diseases - specifically dyslipidemia and hypertension - were found to be common among people with HIV in Puerto Rico. Certain characteristics such as age, sex, and use of medication may play a role in the comorbidities among people with HIV in Puerto Rico. Findings support the need for creating awareness of the comorbidities of people living with HIV, particularly when implementing prevention strategies and prescribing drug therapy. Further, this information should be available to physicians and other health care providers to improve differentiated and comprehensive approaches to address the needs of people with HIV.

\section{Ethics and consent to participate}

The Human Research Subjects Protection Office of the University of Puerto Rico-Medical Sciences Campus approved all study procedures; Protocol A9650314. Consent from participants or to publish result was not necessary as the Institutional Review Board of the University of Puerto Rico-Medical Sciences Campus reviewed and approved a Waiver of Authorization for use of protected health information for research purposes. This waiver is consistent with the Declaration of Helsinki as the study does not adversely affect privacy rights and welfare of the individuals whose records were used.

\section{Data sharing statement}

Used during the current study is available from the authors upon reasonable request and with permission of Merck \& Co., Inc., Carolina, Puerto Rico.

\section{Abbreviation list}

AIDS, acquired immune deficiency syndrome; ART, anti-retroviral therapy; BMI, body mass index; BRFF, Behavioral 
Risk Factors Surveillance System; CD4, cluster of differentiation 4; CHD, coronary health disease; FPG, fasting plasma glucose; HDL, high-density lipoprotein; HgbAic, glycosylated hemoglobin; HIV, human immunodeficiency virus; HPV, human papilloma virus; H2 blockers, histamine H2-receptor antagonists; LDL, low-density lipoprotein; QDS, Questionnaire Development System; SD, standard deviation; TIA, transient ischemic attack; US, United States.

\section{Acknowledgments}

Our gratitude to our community collaborators who granted access to the patients' medical records, Dr Wigberto Gonzalez who supported data collection, and to the graduate and undergraduate students from the University of Puerto Rico who supported other research activities related to this project. This paper was presented at the Conference HIV \& Hepatitis in the Americas as a poster presentation with interim findings. The poster's abstract was published in the Journal of the International AIDS Society, Volume 19, Issue 2S1: 10.7448/IAS.19.2.21033. Financial support for this study was provided by Merck \& Co., Inc., Carolina, Puerto Rico.

\section{Author contributions}

All authors contributed to data analysis, drafting or revising the article, gave final approval of the version to be published, and agree to be accountable for all aspects of the work.

\section{Disclosure}

YR-S, JCO, FA, and HM were employed by Merck \& Co., Inc., Carolina, Puerto Rico, at the time the study was conducted. The authors report no other conflicts of interest in this work.

\section{References}

1. World Health Organization. HIV/AIDS. Available from: https://www. who.int/en/news-room/fact-sheets/detail/hiv-aids 2018. Accessed June $12,2019$.

2. Centers for Disease Control and Prevention. Diagnosis of HIV infection in the United States and dependent areas, 2015. HIV Surveillance Report. 2016; 27.

3. Puerto Rico Department of Health, AIDS Surveillance System. Puerto Rico AIDS surveillance. HIV and AIDS cases reported as of May. 2019, 31.

4. Centers for Disease Control and Prevention. Incidence and diagnoses of HIV infection - Puerto Rico, 2006. MMWR. 2009;58:589-591.

5. Hall HI, Song R, Rhodes P, et al. Estimation of HIV incidence in the United States. JAMA. 2008;300:520-529. doi:10.1001/jama.300.5.520
6. Centers for Disease Control and Prevention. Subpopulation estimate from the HIV incidence surveillance system - united States, 2006. MMWR. 2008;57:985-989.

7. Puerto Rico Health Department. People diagnosed with HIV/AIDS in Puerto Rico. HIV/AIDS Surveillance Syst. 2016.

8. Marzán-Rodríguez M, Zavala DE, Orengo JC, Varas-Díaz N, Miranda De León S. Mortality analysis in people diagnosed with HIV/AIDS in Puerto Rico from 2003-2011. Int J Coll Res Interal Med Puc Health. 2016;8:435-466.

9. Balderson B, Grothaus L, Harrison R, McCoy K, Mahoney C, Catz S. Chronic illness burden and quality of life in an aging HIV population. AIDS Care. 2013;25:451-458. doi:10.1080/09540121.2012.712669

10. Chalermchai T, Hiransuthikul N, Tangkijvanich P, Pinyakorn S, Avihingsanon A, Ananworanich J. Risk factors of chronic hepatitis in antiretroviral-treated HIV infection, without hepatitis B or C viral infection. AIDS Res and Ther. 2013;10:21. doi:10.1186/1742-6405$10-21$

11. Foster R, Morris S, Ryder N, Wray L, McNulty A. Screening for HIV-infected patients for non-AIDS-related morbidity: an evidencebased model of practice. Sex Health. 2011;8:30-42. doi:10.1071/ SH10021

12. Hasse B, Ledergerber B, Furrer H, et al. Morbidity and aging in HIVinfected persons: the Swiss HIV cohort study. Clin Infect Dis. 2011;53:1130-1139. doi:10.1093/cid/cir626

13. Havlik R, Brennan M, Karpiak S. Comorbidities and depression in older adults with HIV. Sex Health. 2001;8:551-559. doi:10.1071/ SH11017

14. Hedmintas L, Solomon D. HIV and its effects on bone: A primer for rheumatologists. Curr Opin Rheumatol. 2012;24:567-575. doi:10.1097/ BOR.0b013e328356d266

15. Peters B, Post F, Wierzbicki AS, et al. Screening for chronic comorbid diseases in people with HIV: the need for a strategic approach. HIV Med. 2013;14:1-11. doi:10.1111/j.1468-1293.2012.01055.x

16. Rodríguez-Penney A, Ludicello J, Riggs P, et al. Co-morbidities in persons infected with HIV: increased burden with older age and negative effects on health-related quality of life. AIDS Patient Care STDS. 2013;27:5-16. doi:10.1089/apc.2012.0329

17. Solomon P, O’Brien K, Wilkins S, Gervais N. Aging with HIV: A model of disability. J Int Assoc Provid AIDS Care. 2014;13:519-525.

18. Shahrir S, Crothers K. HIV and cardiovascular disease: the impact of cigarette smoking. Curr Cardiov Risk Rep. 2011;5:492-500. doi:10.1007/s12170-011-0197-x

19. Vance D, Mugavero M, Willing J, Raper J, Saag M. Aging with HIV: A cross-sectional study of comorbidity prevalence and clinical characteristics across decades of life. J Assoc Nurses AIDS Care. 2011;22:17-25. doi:10.1016/j.jana.2010.04.002

20. Rahmanian S, Wewers ME, Koletar S, Reynolds N, Ferketich A, Diaz P. Cigarette smoking in the hiv-infected population. Proc Am Thorac Soc. 2011;8:313-319. doi:10.1513/pats.201009-058WR

21. Adelzon PA, Falcão MC, Pacheco AG. Metabolic syndrome in HIVinfected individuals: underlying mechanisms and epidemiological aspects. AIDS Res Ther. 2013;10:1-8.

22. Lui G, Ma RCW, Chook P, et al. Progression of atherosclerosis in HIV-infected individuals-Prospective data from an Asian Cohort. $J$ Acquir Immune Defic Syndr. 2017;75:198-202.

23. Triant V. Cardiovascular Disease and HIV Infection. Curr HIV/AIDS Rep. 2013;10:199-206. doi:10.1007/s11904-013-0168-6

24. Currier J. Update on cardiovascular complications in HIV Infection. Top HIV Med. 2009;17:98-103.

25. Puerto Rico's Department of Health. Causes of Death 2000-2008, Auxiliary Secretariat for Planning and Development. San Juan, Puerto Rico: Division of Statistical Analysis; 2010.

26. Centers for Disease Control and Prevention. Behavioral Risk Factor Surveillance System Survey Data. Atlanta, Georgia: U.S. Department of Health and Human Services, Centers for Disease Control and Prevention; 2017. 
27. Pérez C, Guzmán M, Ortiz A, et al. Prevalence of the metabolic syndrome and its individual components in the San Juan Metropolitan Area of Puerto Rico. Ethn Dis. 2008;18:434-441.

28. Monsanto H, Renta-Muñoz A, Dones W, Cidre C, Orengo JC. The Puerto Rico Cardiovascular Risk Estimation Study (PRCaRES): an exploratory assessment of new patients in physicians' offices. $P R$ Health Sci J. 2014;33:58-64.

29. Centers for Disease Control and Prevention. HIV among people aged 50 and older. Available from: https://www.cdc.gov/hiv/group/age/old eramericans/index.html. 2018. Accessed June 12, 2019.

30. Mayor A, Dworkin M, Quesada L, Rios-Olivares E, Hunter-Mellado R. The morbidity and mortality associated with kidney disease in an HIV infected cohort in Puerto Rico. Ethn Dis. 2010;20:163-167.

31. Santiago-Rodríguez EJ, Mayor A, Fernández-Santos DM, RuizCandelaria Y, Hunter-Mellado RF. Anemia in a cohort of HIV-infected Hispanics: prevalence, associated factors and impact on one-year mortality. BMC Res Notes. 2014;7:439. doi:10.1186/1756-0500-7-439

32. Koenig S, Rodríguez L, Bartholomew C, et al. Long-term antiretroviral treatment outcomes in seven countries in the Caribbean. JAIDS. 2012;59:60-71.

33. Chu C, Umanski G, Blank A, Meissner P, Grossberg R, Selwyn P. Comorbidity-related treatment outcomes among HIV-infected adults in the Bronx, NY. J Urban Health. 2011;88:507-518. doi:10.1007/ s11524-010-9540-7

34. Miranda C, Fernández DM, Ramón RO, Velázquez M, Marow AM, Hunter-Mellado RF. Changes in the socio-demographics, risk behaviors, clinical and immunological profile of a cohort of the Puerto Rican population living with HIV: an update of the Retrovirus Research Center (1992-2008). Bol Asoc Med P R. 2010;102:45-51.
35. Maldonado-Martínez G, Fernández-Santos DM, Ríos-Olivares E, Mayor AM, Hunter-Mellado RF. HIV/AIDS in the Puerto Rican elderly: immunological changes between gender and Body Mass Index. $J$ Health Care Poor Undeserved. 2013;24:94-105. doi:10.1353/hpu.2014.0014

36. Ramírez-Marrero F, Santana-Bagur J, Joyner M, Rodríguez-Zayas J, Frontera W. Metabolic syndrome in relation to cardiorespiratory fitness, active, and sedentary behavior in HIV+ Hispanics with and without lipodystrophy: fitness and metabolic-syndrome in HIV. $P R$ Health Sci J. 2014;33:163-169.

37. Gaynes B, O’Donnell J, Nelson E, Heine A, Zinski A, Edwards M. Psychiatric comorbidity in depressed HIV-infected individuals: common and clinically consequential. Gen Hosp Psychiatry. 2015;37:277-282. doi:10.1016/j.genhosppsych.2015.03.021

38. Kaiser Family Foundation. Gender differences in health care, status, and use: spotlight on men's health. Available from: http://kff.org/ womens-health-policy/fact-sheet/gender-differences-in-health-carestatus-and-use-spotlight-on-mens-health/ Accessed February 20, 2017.

39. Guaraldi G, Zona S, Brothers T, et al. Aging with HIV vs. HIV seroconversion at older age: A diverse population with distinct comorbidity profiles. PLoS One. 2015;10:e118531. doi:10.1371/ journal.pone.0118531
HIV/AIDS - Research and Palliative Care

\section{Publish your work in this journal}

HIV/AIDS - Research and Palliative Care is an international, peerreviewed open-access journal focusing on advances in research in HIV, its clinical progression and management options including antiviral treatment, palliative care and public healthcare policies to

\section{Dovepress}

control viral spread. The manuscript management system is completely online and includes a very quick and fair peer-review system, which is all easy to use. Visit http://www.dovepress.com/testimonials.php to read real quotes from published authors. 